\title{
Gaseous Hydrogen Embrittlement of T-250 Laser Welds
}

\author{
L.W. Tsay, W.B. Huang, and C. Chen
}

\begin{abstract}
The tensile properties of laser-welded T-250 maraging steel are measured, with attention paid to the influence of strain rate and gaseous hydrogen on the fracture behavior of welded specimens. Post-weld heat treatments are performed on laser-welded specimens to obtain underaged (WU), peak-aged (WP), and overaged (WO) specimens. Hydrogen embrittlement (HE) affects the tensile fracture behavior of the welded specimens; HE changes not only the fracture mode but also the fracture location. Without the influence of hydrogen, the fracture location is at the softest region, the weld metal (WM), and the fracture appearance reveals a ductile dimple fracture. For welds sensitive to $\mathrm{HE}$, the fracture is initiated at the heat-affected zone (HAZ) with coarse grain size, and the associated fracture surface exhibits intergranular and quasi-cleavage fractures that are brittle in nature. In addition, the $H A Z$ with coarse grain size is more prone to $\mathrm{HE}$, as compared to other regions in the welded specimens. The WU specimens are susceptible to $\mathrm{HE}$ in air under a low strain rate, while the WP specimens are only susceptible to gaseous hydrogen embrittlement (GHE). However, the WO specimens are immune to GHE and insensitive to strain rate.
\end{abstract}

Keywords

heat-affected zone, intergranular fracture, quasi-cleavage, weld metal

\section{Introduction}

VASCOMAX T-250 (Teledyne Vasco), a Ti-strengthened maraging steel, is an ultra-high-strength alloy that was developed in the early $1980 \mathrm{~s}$. It has a nominal yield strength of $1724 \mathrm{MPa}$ $(250 \mathrm{ksi})$ and a plane strain fracture toughness $\left(K_{\mathrm{lc}}\right)$ greater than $99 \mathrm{MPa} \sqrt{\mathrm{m}}$ in the peak-aged condition (Ref 1-2). Superior strength and toughness together with good formability make this alloy very attractive as a structural material for critical applications. T-250 maraging steel can be hardened by a refined distribution of $\mathrm{Ni}_{3} \mathrm{Ti}$ precipitates, which are coherent with the matrix in the underaged condition and lose their coherency as the aging temperature increases ( Ref 3 ). In the overaged T-250 maraging steel, the extensive formation of reverted austenite not only causes the substantial change in mechanical properties but also reduces the susceptibility to hydrogen embrittlement (HE) (Ref 4). A previous study on aged T-250 maraging steel (Ref 4 ) indicates that the peak-aged specimens are susceptible to gaseous hydrogen embrittlement (GHE). At low strain rates, the underaged specimens suffer severe embrittlement even in air (Ref 4). High-strength martensitic steels are very susceptible to GHE (Ref 5-6), and the aggressive nature of hydrogen may cause catastrophic failure of structural components, especially in heavily stressed joints.

The low carbon content in T-250 results in an excellent weldability, which is an important consideration in engineering applications. However, the segregation of alloying elements in the weld metal (WM) and the formation of the heat-affected zone (HAZ) might change the susceptibility to HE and the mechanical properties of the material. The use of laser beam welding minimizes the heat input ( $\operatorname{Ref} 7$ ), which, in turn, reduces the

L.W. Tsay and W.B. Huang, Institute of Materials Engineering, $\mathrm{Na}$ tional Taiwan Ocean University, Keelung, Taiwan, R.O.C.; Fax: 8862-4625324; and C. Chen, Institute of Materials Science and Engineering, National Taiwan University, Taipei, Taiwan, R.O.C.; Fax: 886-2-3925330. extent of solute segregation in the WM and the distortion of the weldment. Because the high power-density of this process produces high-quality welds with a high depth-to-width ratio and a narrow HAZ, the process has been widely used to improve productivity in various industries (Ref 8-9). On the other hand, the welding process inevitably introduces structural and/or compositional inhomogeneity within the material. This inhomogeneity could affect the mechanical properties and the performance in hydrogen-containing environments of the alloy.

The present study is undertaken to gain a better understanding of the HE susceptibility of T-250 laser welds. The effects of strain rate and testing environment on the tensile properties of the welds are investigated after various aging treatments are performed. In particular, the fracture location and the associated fractography of tensile specimens are examined.

\section{Experimental Procedure}

The chemical composition (wt \%) of the T-250 maraging steel used in this investigation is $18.63 \mathrm{Ni}, 3.09 \mathrm{Mo}, 1.38 \mathrm{Ti}$, $0.006 \mathrm{C}, 0.002 \mathrm{~S}, 0.004 \mathrm{P}$, and balance Fe. The steel plate $(3.4$ $\mathrm{mm}, 0.14 \mathrm{in}$. thick) prior to laser welding is solution-treated at $816^{\circ} \mathrm{C}\left(1500^{\circ} \mathrm{F}\right)$ for $1 \mathrm{~h}$ and then air cooled. For the laser welding experiments, a commercially available $\mathrm{CO}_{2}$ laser (RofinSinar 850) is employed to perform autogenous welding. The processing variables used to conduct bead-on-plate welds are listed in Table 1. Post-weld heat treatments (PWHTs) of the

Table 1 Laser welding parameters used in the experiment

$\begin{array}{ll}\text { Laser power } & 2500 \mathrm{~W} \\ \text { Travel speed } & 700 \mathrm{~mm} / \mathrm{min}(28 \mathrm{in} . / \mathrm{min}) \\ \text { Focal lens } & \mathrm{ZnSe} \\ \text { Focal length } & 190.5 \mathrm{~mm}(7.5 \mathrm{in}) \\ \text { Focal point } & 0.5 \mathrm{~mm}(0.02 \mathrm{in}) \text { Underfocus }(0.5 \mathrm{~mm} \\ & \text { below the surface }) \\ \text { Plasma assist gas flow rate } & 25 \mathrm{U} / \mathrm{min}, \mathrm{He} \\ \text { Backing gas flow rate } & 25 \mathrm{~L} / \mathrm{min}, \mathrm{Ar}\end{array}$


welded specimens are performed at $426^{\circ} \mathrm{C}\left(800^{\circ} \mathrm{F}\right), 482^{\circ} \mathrm{C}$ $\left(900^{\circ} \mathrm{F}\right)$, and $593^{\circ} \mathrm{C}\left(1100^{\circ} \mathrm{F}\right)$ for $4 \mathrm{~h}$. The specimens for the tensile testing are made with the rolling direction of the steel plate perpendicular to the welding direction. The dimension of tensile specimens with a gage length of $25 \mathrm{~mm}$ (1 in.) for laser welds is sketched in Fig. 1. The preparation of tensile specimens included: cutting the specimen's profile using an electrodischarge machine with wire electrode; grinding the specimens to the required thickness of $3.0 \mathrm{~mm}(0.12 \mathrm{in}$.); and polishing the surface of the gage length. Constant extensionrate tensile tests are performed at room temperature in air with strain rates of $5 \times 10^{-3} \mathrm{~s}^{-1}$ and $5 \times 10^{-6} \mathrm{~s}^{-1}$. In order to investigate the effect of gaseous hydrogen on tensile properties, the welded specimens are also tested in a stainless steel chamber with hydrogen at $2 \mathrm{~atm}$ under a strain rate of $5 \times 10^{-6} \mathrm{~s}^{-1}$. Since the WM is located at the center of the gage length, as shown in Fig. 1, the HE susceptibility associated with various regions containing distinct microstructural features in the welds could be established. The results of mechanical properties are the average of at least three specimens for each testing condition. The fracture surfaces of tensile specimens are then carefully examined by scanning electron microscopy (SEM), particularly in the welded regions, that is, the HAZ and the WM. In addition, metallographic examinations and microhardness measurements using a Vickers hardness tester are carried out to characterize various regions in the welds.

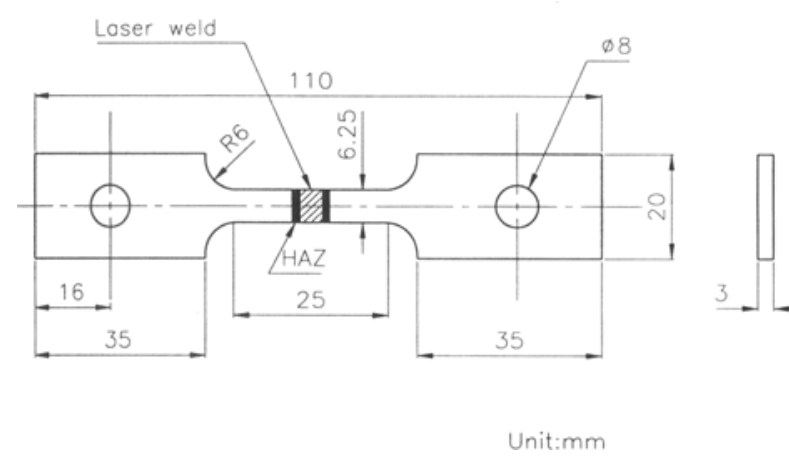

Fig. 1 Schematic showing the dimension of laser-welded specimens used in tensile tests

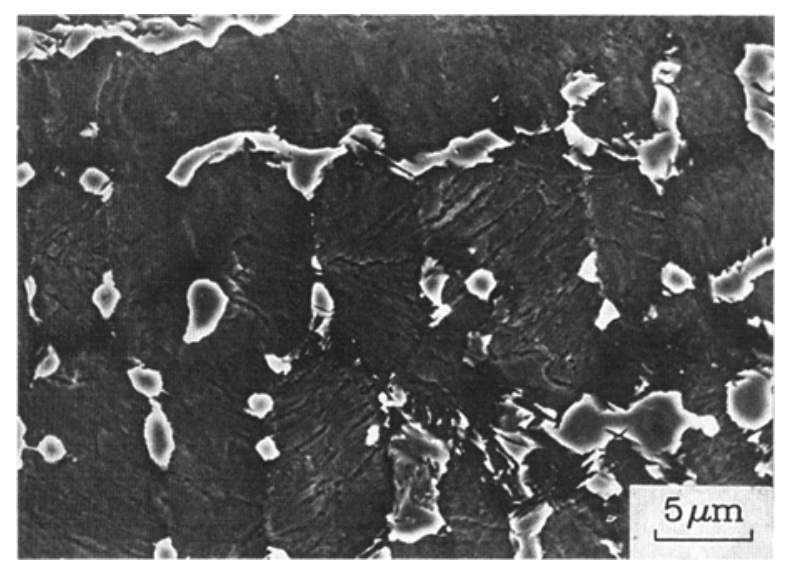

Fig. 2 Typical SEM photograph showing austenite pools in the WM of a WP specimen

\section{Results and Discussion}

Laser-welded specimens which are post-weld heat treated at $426{ }^{\circ} \mathrm{C}$ (underaged), $482{ }^{\circ} \mathrm{C}$ (peak-aged), and $593{ }^{\circ} \mathrm{C}$ (overaged) are assigned WU, WP, and WO, respectively, for specimen identifications. The Vickers hardness values in distinct regions of the welds after various PWHTs are given in Table 2. This table indicates that the lowest hardness is associated with the WM, and the HAZ always has a lower hardness than the BM for all these specimens. When comparing the hardness in a given region of the welds, the WP specimens have the highest hardness, followed by the WU specimens, while the WO specimens have the lowest hardness. The WP specimens also present the most significant reduction in hardness within the WM (HV 480 ), as compared to the BM (HV 540).

The precipitation sequence in the WM and the $\mathrm{HAZ}$ resembles that in the BM of the maraging steel welds (Ref 10-12). However, the size and the amount of austenite pools in the WM increases as the PWHT temperature of the welds is raised (Ref 13). The more reverted austenite in the WM, the less strengthening elements ( $\mathrm{Ti}$ and $\mathrm{Mo}$ ) are available for hardening. Figure

Table 2 The hardness values (HV) in distinct regions of the welds after various PWHTs

\begin{tabular}{lccc}
\hline & \multicolumn{3}{c}{ Specimen } \\
\cline { 2 - 4 } Region & WU & WP & WO \\
\hline BM & 505 & 540 & 415 \\
HAZ & 495 & 505 & 405 \\
WM & 460 & 480 & 370 \\
\hline
\end{tabular}

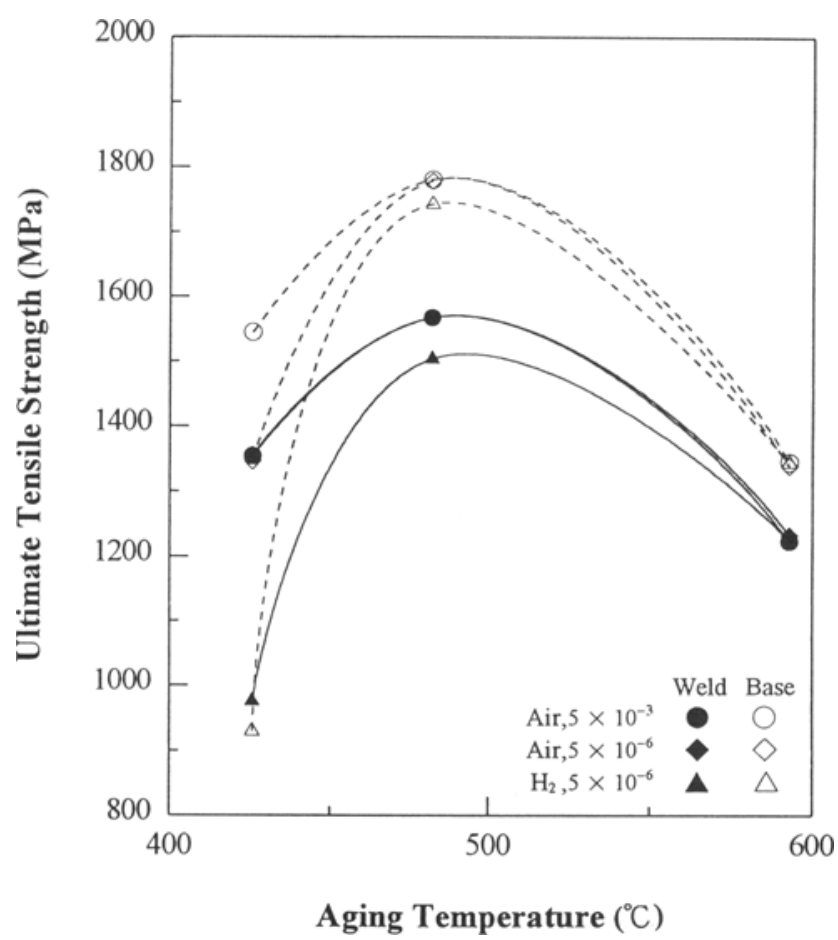

Fig. 3 Comparison of tensile strengths between laser welds and base plates (Ref 4$)$ with similar aging treatments under various testing conditions 
Table 3 Tensile results of laser-welded specimens under various testing conditions

\begin{tabular}{|c|c|c|c|c|c|c|c|}
\hline \multirow{2}{*}{$\begin{array}{l}\text { Specimen } \\
\text { identification }\end{array}$} & \multirow[b]{2}{*}{ Environment } & \multirow{2}{*}{$\begin{array}{c}\text { Strain rate, } \\
\mathbf{s}^{-1} \\
\end{array}$} & \multicolumn{2}{|c|}{ UTS } & \multirow{2}{*}{$\begin{array}{c}\text { Elongation, } \\
\% \\
\end{array}$} & \multirow{2}{*}{$\begin{array}{c}\text { Reduction in area, } \\
\% \\
\end{array}$} & \multirow{2}{*}{$\begin{array}{l}\text { Fracture } \\
\text { location }\end{array}$} \\
\hline & & & $\mathbf{M P a}$ & ksi & & & \\
\hline \multirow[t]{3}{*}{ WU } & Air & $5 \times 10^{-3}$ & 1354 & 196.4 & 4.7 & 28.8 & WM \\
\hline & & $5 \times 10^{-6}$ & 1356 & 196.6 & 2.3 & 6.0 & HAZ/WM \\
\hline & Hydrogen & $5 \times 10^{-6}$ & 975 & 141 & 2.1 & 5.4 & HAZ/WM \\
\hline \multirow[t]{3}{*}{ WP } & Air & $5 \times 10^{-3}$ & 1567 & 227.3 & 3.5 & 20.2 & WM \\
\hline & & $5 \times 10^{-6}$ & 1568 & 227.4 & 3.8 & 19.3 & WM \\
\hline & Hydrogen & $5 \times 10^{-6}$ & 1504 & 218 & 2.7 & 9.8 & HAZ/WM \\
\hline \multirow[t]{3}{*}{ wo } & Air & $5 \times 10^{-3}$ & 1224 & 177.5 & 8.0 & 32.4 & WM \\
\hline & & $5 \times 10^{-6}$ & 1234 & 178.9 & 7.6 & 30.2 & WM \\
\hline & Hydrogen & $5 \times 10^{-6}$ & 1227 & 177.9 & 7.4 & 28.7 & WM \\
\hline
\end{tabular}

Note: WU, Laser welded $+426^{\circ} \mathrm{C} / 4 \mathrm{~h}$ (underaged); WP, Laser welded $+482^{\circ} \mathrm{C} / 4 \mathrm{~h}$ (peak-aged); WO, Laser welded $+593^{\circ} \mathrm{C} / 4 \mathrm{~h}$ (overaged); UTS, ultimate tensile strength.

2 is a typical SEM photograph showing austenite pools in the WM of a WP specimen. Neither reverted austenite nor austenite pools are found in the BM and the HAZ of WU and WP specimens, while an extensive amount of reverted austenite is present in the WO specimen. The microstructures of the underaged and peak-aged specimens consist of coherent and partially coherent $\mathrm{Ni}_{3} \mathrm{Ti}$ precipitates, respectively (Ref 3 ). The existence of coarse $\mathrm{Ni}_{3} \mathrm{Ti}$ (incoherent precipitates) and the significant amount of reverted austenite cause the reduced susceptibility to HE of the overaged specimens (Ref 4). This level of susceptibility is consistent with the report that reverted austenite could limit the nucleation of emissary cracks ahead of the main crack front (Ref 14).

Tensile results of T-250 laser welds which are tested under various conditions are given in Table 3 , together with the fracture location of tensile specimens. Decreasing the strain rate could promote interaction between the crack tip and the hydrogen in the environment. All welded specimens exhibit localized necking when the fracture locations are in the WM. When the strain rate is reduced from $5 \times 10^{-3} \mathrm{~s}^{-1}$ to $5 \times 10^{-6} \mathrm{~s}^{-1}$, the WU specimens show a similar ultimate tensile strength (UTS) but a drastic decrease in reduction in area (RA) when tested in laboratory air. However, inferior tensile properties are obtained for WU specimens tested in hydrogen under a $5 \times 10^{-6} \mathrm{~s}^{-1}$ strain rate, in which the tensile strength is greatly reduced. For WP specimens, tensile properties remain nearly the same as the strain rate is decreased from $5 \times 10^{-3} \mathrm{~s}^{-1}$ to $5 \times 10^{-6} \mathrm{~s}^{-1}$ when tested in air. However, severe embrittlement occurs for WP specimens in hydrogen $(\mathrm{RA}=9.8 \%)$. The WO specimens are insensitive to strain rate and immune to GHE; the RAs are about $30 \%$. For specimens tensile-fractured in the HAZ/WM, no necking is observed, and the RA is less than $10 \%$. The tensile strengths of welded specimens after various PWHTs are, in general, less than those of the base plates with similar aging treatments, as shown in Fig. 3. The comparison of ductility between the laser welds and the base plates is not made, since the deformation behavior is quite complicated in the welded specimens. Such complications arise from the distinct mechanical properties and $\mathrm{HE}$ susceptibilities of various regions within the gage length of a tension specimen (Fig. 1), and the plastic deformation in one region is also constrained by the others.

Without the effect of $\mathrm{HE}$, for example, in specimens tested in air with a high strain rate of $5 \times 10^{-3} \mathrm{~s}^{-1}$, the location of ten- sile fractures is always in the WM. The coarse columnar structure and the segregation of $\mathrm{Ti}$ and Mo to interdendritic boundaries to form austenite pools in the subsequent PWHTs causes a low hardness in the WM. As a result, the plastic deformation is concentrated at this narrow WM and eventually leads to fracture. Table 2 shows that the WM has the lowest hardness among various regions of the weld. Therefore, the tensile fracture at this region is expected.

For those specimens which are sensitive to HE, such as WU specimens tested in air with a strain rate of $5 \times 10^{-6} \mathrm{~s}^{-1}$ and WP specimens tested in $\mathrm{H}_{2}$, the fracture is initiated at the coarsegrained $\mathrm{HAZ}$ and propagated into the WM. The fracture location is, therefore, represented as HAZ/WM in Table 3. The RA under this situation depends on the proportion of the HAZ to the WM at the location of measurements; in other words, the lower the RA, the higher the ratio of the HAZ to the WM. A low RA of the tensile specimen would also indicate the influence of hydrogen in causing premature failure. The results also suggest that the HAZ in WU and WP specimens is more prone to $\mathrm{HE}$ than other regions of the welds. The same is not true for the welds in the overaged condition; the HAZ and the BM of WO specimens are not susceptible to $\mathrm{HE}$. In the WO specimen, the average hardness if $415 \mathrm{HV}$ for the BM, $405 \mathrm{HV}$ for the HAZ, and $370 \mathrm{HV}$ for the WM, as indicated in Table 2. Consequently, the fracture is initiated and eventually fractured at the weakest region, the WM of WO specimens. This finding is in agreement with the results of T-250 base plates, in which the overaged specimens have excellent resistance to GHE (Ref 4). Figure 4(a) shows the reverted austenite in the BM, in which the reverted austenite not only decorates grain boundaries but also forms a lamellar structure in the grain interior of the WO specimen. The structure in the HAZ is similar to that in the BM of the WO specimen, except for a larger grain size in the HAZ (Fig. 4b).

Fractographic observations are made on tensile-fractured specimens with emphasis on the crack initiation site and the near-surface region. The influence of hydrogen, if any, would be most severe in these locations (Ref 15). The WU specimens are very sensitive to strain rate when tested in air. As the strain rate is lowered, the RA suffers a great loss (28.8 versus $6 \%$ ) in air, as illustrated in Table 3 . The fracture appearance of WU specimens alters from a ductile fracture mode (Fig. 5a) at a high strain rate of $5 \times 10^{-3} \mathrm{~s}^{-1}$ to intergranular/quasi-cleavage mixed 

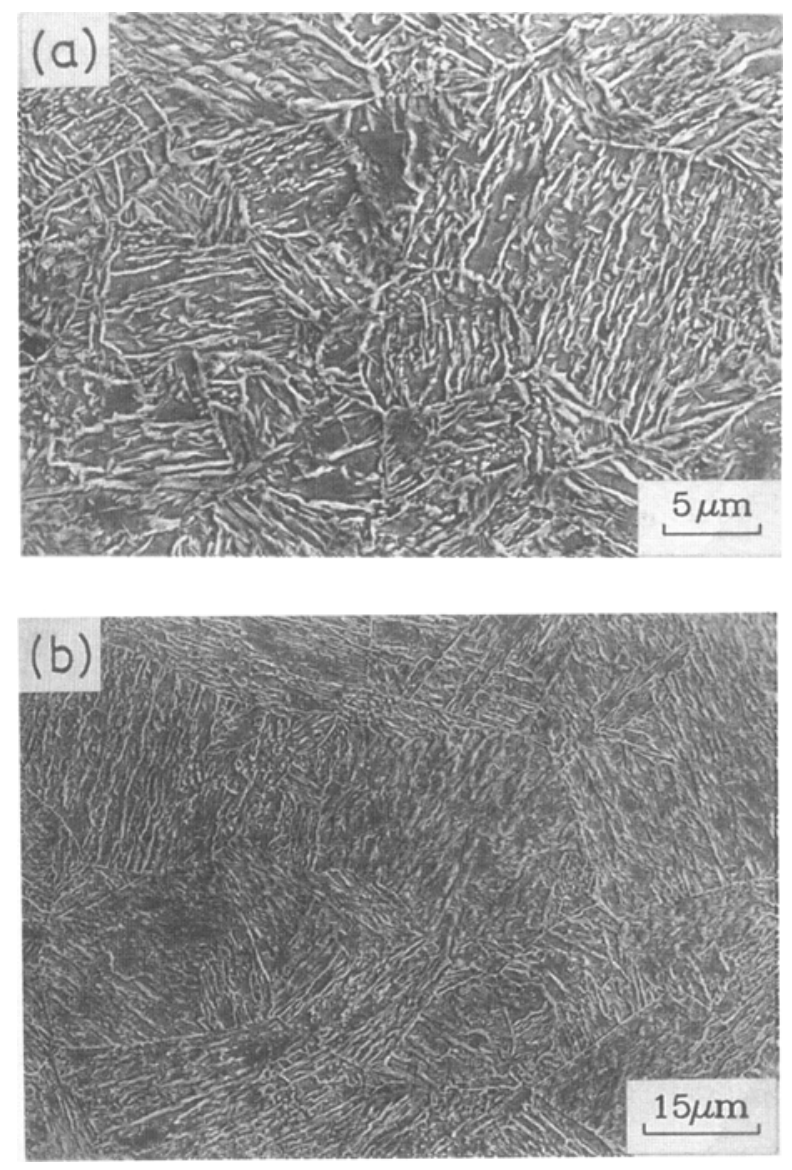

Fig. 4 SEM metallographs revealing (a) the BM and (b) the HAZ of a WO specimen

fracture modes (Fig. 5b) at a low strain rate of $5 \times 10^{-6} \mathrm{~s}^{-1}$. The changes in fracture modes are also associated with a change in the fracture location, that is, from the WM to the $\mathrm{HAZ/WM}$. More intergranular fracture and secondary cracks along the prior austenite grain boundaries (Fig. 5c) are observed for the WU specimen tested in $\mathrm{H}_{2}$ at a strain rate of $5 \times 10^{-6} \mathrm{~s}^{-1}$, and the fracture location is in the HAZ/WM. The foregoing results also imply that the WM containing austenite pools is more resistant to $\mathrm{HE}$ than the coarse-grained HAZ in the WU specimen.

For the WP specimens, the decrease in strain rate has no apparent effect on tensile properties in air. The tensile strength and ductility remain almost the same for $5 \times 10^{-3} \mathrm{~s}^{-}$ ${ }^{1}$ to $5 \times 10^{-6} \mathrm{~s}^{-1}$ strain rates. The fracture appearance of these specimens exhibits a dimple fracture in air under a strain rate of $5 \times 10^{-6} \mathrm{~s}^{-1}$. However, the WP specimens are susceptible to GHE. Quasi-cleavage with secondary cracks along prior austenite grain boundaries are found for such specimens tested in $\mathrm{H}_{2}$ (Fig. 6). In the case of the WO specimens, the tensile results are similar regardless of testing environments and strain rates. This result is consistent with the conclusion of T-250 aged maraging steel that neither embrittlement nor strain rate sensitivity is found in the overaged specimens (Ref 4). The fracture appearance of WO specimens reveals essentially a ductile fracture mode even in the gaseous hydrogen environment.
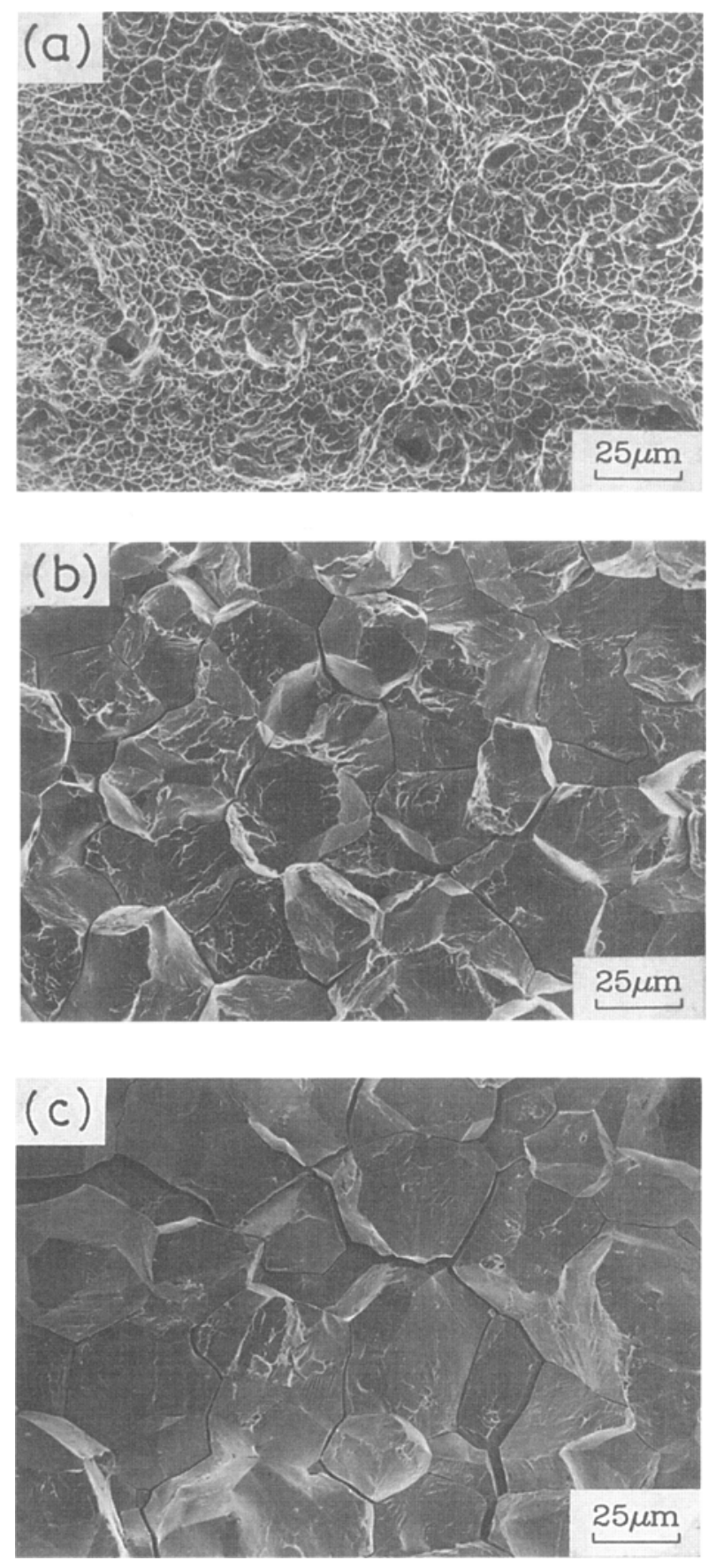

Fig. 5 SEM fractographs showing the WU specimens tested in (a) air with $5 \times 10^{-3} \mathrm{~s}^{-1}$ strain rate, (b) air with $5 \times 10^{-6} \mathrm{~s}^{-1}$ strain rate, and (c) $\mathrm{H}_{2}$ with $5 \times 10^{-6} \mathrm{~s}^{-1}$ strain rate

\section{Conclusions}

- While the formation of austenite pools causes a significant hardness drop in the WM of the welds after PWHTs, the austenite has the benefit of reducing the susceptibility to HE in the WM of T-250 laser welds.

- The hardness in the HAZ is higher than the WM but lower than the BM of the welds, regardless of various PWHTs. However, the $\mathrm{HAZ}$ with coarse grain size is more prone to 


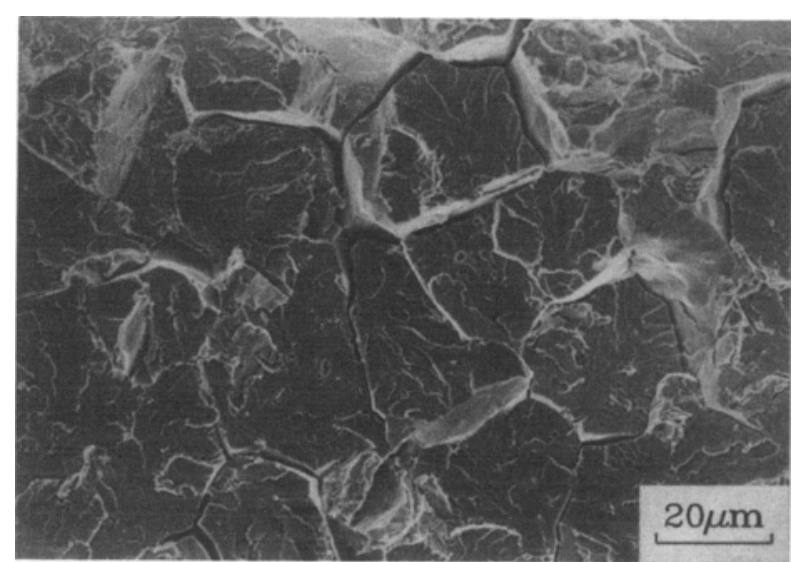

Fig. 6 SEM fractograph showing a WP specimen tested in $\mathrm{H}_{2}$ with $5 \times 10^{-6} \mathrm{~s}^{-1}$ strain rate

$\mathrm{HE}$, as compared to other regions in welded specimens that are aged to and/or tested in susceptible conditions.

- Without the influence of $\mathrm{HE}$ the tensile-fractured locations are in the WM, and the fracture surfaces exhibit a ductile dimple fracture. These results include the WU specimens tested in air with a high strain rate and the WP specimens tested in air. The WO specimens are insensitive to strain rate and immune to $\mathrm{GHE}$.

- For welds susceptible to HE, the fracture is initiated at the coarse-grained HAZ and propagated into the WM. The fracture appearance reveals intergranular/quasi-cleavage for the WU specimens and quasi-cleavage with secondary cracks along the prior austenite grain boundaries for the WP specimens.

\section{Acknowledgment}

The authors gratefully acknowledge the support of the Republic of China National Science Council (contract No. 84 NSC-2216-E019-006).

\section{References}

1. S. Floreen and A.M. Bayer, Development and Commercialization of Cobalt-Free Maraging Steels, Symposium of TMS Annual Meeting (Phoenix, AZ), TMS, 1988, p 39

2. C.F. Hickery, Jr. and T.S. Thomas, Mechanical Characterization of Vasco Max T-250, Symposium of TMS Annual Meeting (Phoenix, AZ), TMS, 1988, p 73

3. V.K. Vasudevan, S.J. Kim, and C.M. Wayman, Metall. Trans. A, Vol 21 (No. 10), 1990, p 2655

4. L.W. Tsay, W.B. Huang, Y.M. Li, and C. Chen, Hydrogen Embrittlement of a Ti-Strengthened 250 Grade Maraging Steel, $J$. Mater. Eng. Perform., Vol 6 (No. 2), April 1997, p 177-181

5. D.P. Williams and H.G. Nelson, Metall. Trans., Vol 1 (No. 1), 1970, p 63

6. D. Hardie and S. Liu, Corros. Sci., Vol 38 (No. 5), 1996, p 721

7. J. Mazumder and W.M. Steen, Metall. Trans. A, Vol 13 (No. 5), 1982, p 865

8. M. Peters and J.C. Williams, Metall. Trans. A, Vol 15 (No. 8), $1984, p 1589$

9. R.A. Hella, Opt. Eng., Vol 17 (No. 3), 1978, p 198

10. S. Floreen and R.F. Decker, Trans. Q., ASM, Vol 55 (No. 3), 1962, p 518

11. R.F. Decker and S. Floreen, Maraging Steel-The First 30 Years, Symposium of the TMS Annual Meeting (Phoenix AZ), TMS, 1988, p 1

12. F.H. Lang and N. Kenyon, Welding of Maraging Steels, Weld. Res. Counc. Bull., 1971, No. 159

13. L.W. Tsay, C. Chen, and S. Chan, Int. J. Mater. Prod. Technol,, Vol 10 (No. 1/2), 1955, p 132

14. S.D. Antolovuch, A. Saxena, and G.R. Chanani, Metall. Trans., Vol 5 (No. 3), 1974, p 623

15. I.O. Shin and J.G. Byrne, Mater. Sci. Eng., A, Vol 123 (No. 2), 1990, p 169 